\title{
Prevalence of Urinary Tract Infection Causing Microorganism and Determination of Susceptibility to Antibiotic among Slum Women of District Varanasi, India
}

\author{
Bharti Singh ${ }^{1}$, Deepmala Katiyar ${ }^{2 *}$, Ragini Tilak ${ }^{1}$, \\ Ratan Kumar Srivastava $^{3}$ and Rajveer Singh Chauhan ${ }^{4}$ \\ ${ }^{1}$ Department of Microbiology, Institute of Medical Sciences, \\ Banaras Hindu University, Varanasi, India \\ ${ }^{2}$ Department of Plant Physiology, Institute of Agricultural Sciences, \\ Banaras Hindu University, Varanasi, India \\ ${ }^{3}$ Department of Community Medicine, Institute of Medical Sciences, \\ Banaras Hindu University, Varanasi, India \\ ${ }^{4}$ VitaeGen Biotech-Educational and Research Institute (Run by RED Society), \\ Varanasi, India \\ *Corresponding author
}

\section{A B S T R A C T}

\begin{tabular}{|l|}
\hline Ke y w o r d s \\
$\begin{array}{l}\text { Urinary Tract } \\
\text { Infection (UTI), E. } \\
\text { coli, Slums, } \\
\text { Varanasi }\end{array}$ \\
\hline Article Info \\
\hline $\begin{array}{l}\text { Accepted: } \\
\text { 28 January } 2018 \\
\text { Available Online: } \\
\text { 10 February } 2018\end{array}$ \\
\hline
\end{tabular}

Urinary tract infections (UTIs) are among the most common bacterial infections. Enteric bacteria predominantly Escherichia coli) remain the most frequent cause of UTIs, although the distribution of pathogens that cause UTIs is changing. The study was based on primary survey to five different slums (Ravindrapuri extension, Nagwan, Bajardeehan, Batuapura and Ghasiyari Tola) of Varanasi city. This study is an attempt to determine the UTI status in slums of Varanasi city. During Questionnaire session we found that only 6\% women were aware of UTI. 398 samples from slums were cultured on CLED, HI chrome, MSA, and preceded for biochemical identification followed by antimicrobial susceptibility tests using first line drug. 183 episodes of UTI were observed out of 398 . We found $48 \%, 45 \%$, $49 \%, 42 \%, 35.4 \%$ women suffered from UTI in Ravindrapuri Extension, Nagwan, Bajardeehan, Batuapura and Ghasiyari Tola slums respectively. Highest number of gram negative E.coli and gram positive S. aureus found in all slums. More important is the increase in resistance to some antimicrobial agents, mainly the resistance to ampicillin, cefozolin, gentamicin, ofloxacin seen in E. coli.

\section{Introduction}

Urinary tract infection (UTI) is the second most common infectious presentation in community medical practice. Worldwide, about 150 million people are diagnosed with UTI each year, and UTI are classified as uncomplicated or complicated (Stamm and
Norrby, 2001). UTI is one of the most frequently encountered bacterial infections in infants and children, and the most common bacterial infection in infants under three months of age (Stanley, 2005). Approximately $50 \%$ of women will suffer from at least once urinary tract infection (UTI) during their adult life. According Standing Medical Advisory 
Sub-group on Antimicrobial Resistance (1998), UTIs account for around 5\% of consultations in General Practice and are the second commonest infection after respiratory infections. $15 \%$ of community use of antibiotics is for UTIs. A few women will suffer significant morbidity from the effects of pyelonephritis, an infection of the kidney substance, usually caused by infection ascending from the bladder. Most of those suffering morbidity will have underlying causator abnormalities. $25 \%$ of those who have had one infection will have at least one further infection, and sometimes, multiple recurrences (Stapleton, 1999). More than 95\% of urinary tract infections are caused by a single bacterial species. E. coli is the most frequent infecting organism in acute infection (Ronald, 2002).

Though urbanisation is an indicator of development, but it is also bitter fact that poverty is growing faster in urban areas than in rural areas. Being a complex socioeconomic process closely connected with scientific technological revolution, urbanisation exercises a growing influence on all aspects of society, reflecting the nature of economic and regional development (Rao and Padmanabha, 1999). Around the world, one billion people live in urban slums, which are typically overcrowded, polluted and lack basic services. One of the targets set by world leaders in 2000 was to improve significantly the lives of at least 100 million slum dwellers by 2020 . The situation is worst in developing countries like India. Varanasi, one of the oldest living city of the world, also faces the challenges of rapid urbanisation. The slums of Varanasi portray a pathetic picture of life in slums (Tripathi, 2011). Total wards in Varanasi Metropolitan Corporation are 106, amongst these wards the slum dwells only in 61 wards. The population of urban poor and slum dwellers in Varanasi accounts for about $37.69 \%$ of the city population. Varanasi has 227 slums spread all over the city, either on government or private lands. About $50 \%$ of slums are located in central city, $13 \%$ in old city while $37 \%$ in peripheral areas. The average density in slum areas is approximately 330 persons per hectare in the city area (Jha and Tripathi, 2014). The study was attempted to explore UTI status and occurrence of bacterial strain of slum dwellers and suggest some measures of inclusive development and provide vision to improve quality of life in slums by reducing incidence of UTI.

\section{Materials and Methods}

The study area Varanasi (Kashi or Banaras) is one of the oldest living city in the world, with a continuous history dating back 3,000 to 5,000 years. It is known as cultural and spiritual capital of India. Varanasi $\left(82^{\circ} 56^{\prime} \mathrm{E}-\right.$ $83^{\circ} 03^{\prime} \mathrm{E}$ and $25^{\circ} 14^{\prime} \mathrm{N}$ ) is located on the left crescent-shaped bank of the Ganga river. Slums in Varanasi city has been continuously increasing from 1941 to 2017. With the increase in population of the city, housing needs of the city also grew, which could not be met out by the formal housing market. Migrating population, which could not avail the facilities of formal housing market, satisfied their needs by occupying vacant land and this has resulted in formation of slums. Another factor, which contributes in the formation of slums, is proximity to work place and low level of income and un-affordability of houses People living in the slums of Varanasi city are poor working as labour and rickshaw pullers.

\section{Selected slums}

Ravindrapuri extension, Nagwan, Bajardeehan, Batuapura and Ghasiyari Tola

\section{Survey}

The following tool was used for survey.

Questionnaire prepared in the local language provided to women. The questions were 
mainly dichotomous items with Yes OR No choices and avoided personal, complicated and misleading questions. The questions were direct and brief. It included: personal data, age, marital status, occupation, previous history of UTI, risk factors, hygiene habits, the antibiotics use.

\section{Diagnosis}

\section{Collection of Samples}

867samples of urine were collected from 4 villages (Neguran, Mustafapur, Bindpurvan \& Gauri) and 5 Slums Ravindrapuri extension, Nagwan, Bajardeehan, Batuapura, and Ghasiyari Tola. Brief history of patients was obtained about frequency of micturation, retention of urine, burning micturation, fever and chills.

The samples were collected in pre-sterile, dry, wide-mouthed and leak proof universal plastic containers. Samples were immediately transported to the laboratory where they were processed promptly.

\section{Isolation of bacteria}

$1 \mathrm{ul}(.001 \mathrm{ml})$ wire loop was sterilized and dipped into a urine sample. The loop was then streaked on the plate of cysteine lactose electrolyte deficient (CLED) Agar. The plates were incubated overnight at $37^{\circ} \mathrm{C} \dot{\mathrm{c}}$ for 24 hours. Following the appearance of growth, well-isolated bacterial colonies were processed biochemical and for antibiotic sensitivity tests. The number of colonies on CLED plate was counted and viable count of bacteria was reported for each specimen

\section{Identification of bacterial isolates}

Culture media were prepare for the purpose making biochemical test of the bacterial isolates and studied following the completion of diagnosis:
Characteristics manifestation of the developing colonies

Observed qualities manifestation of the colonies developing on culture media form color, the surface of the colony, strength, transparency, smell, on HiChrome, MSA.

\section{Microscopic characteristics of the developing colonies}

Swabs were the work of the pure colonies segments of slides the colored character gram stain observed forms of cells, arranged, responding to gram stain

\section{Biochemical Tests}

Tests conducted a production of the enzyme Catalase, Oxidase, Coagulase as stated in Motility test, Urease, Indol, $\mathrm{H}_{2} \mathrm{~S}$ Production, Citrate utilization, Sugar fermentation.

\section{Sensitivity to antibiotics}

From the use of first line drug of antibiotics are: determining sensitive and resistant bacteria to antibiotics by measuring the diameter of inhibition zone by $\mathrm{mm}$ and then compared with the standard diameters that installed in the standard scales.

\section{Results and Discussion}

A close ended questionnaire for the symptomatic women were designed and translated into local language to prevent misunderstanding. The questions were mainly dichotomous items with Yes OR No choices and avoided personal, complicated and misleading questions. The questions were direct and brief. It included: personal data, age, marital status, occupation, previous history of UTI, risk factors, hygiene habits, the antibiotics use. 


\section{Ravindrapuri extension slum}

On the basis of questionnaire, 110 samples of highly symptomatic women were then collected from Ravindrapuri extension slum. Samples were cultured in laboratory and then organized in different age groups. The result showed that the overall prevalence of UTIs in both age groups was $48 \%$. In which, occurrence of UTI in 15-30 age group was found upto $64 \%$ while $31-45$ age group showed $35.8 \%$. Thus, $15-30$ age group show increased risk of infection than 31-45 age group females. Women of 15-30 years age group were reported to have two folds increase UTI as compared to the 31-45 age groups (Table 1).

Almost all of the cases of UTIs were due to the gram negative bacteria with no prominent age group difference. The percentage of gram negative bacteria was $52.8 \%$. The percentage of Lactose fermenting bacteria was $78.5 \%$. Lactose fermenting (78.5\%) bacteria indicated predominant frequency in both age groups. Non lactose fermenting bacteria was observed $21.4 \%$.

The age group 15-30 years females demonstrated about two folds increase of NLF than 31-45 age group females (Table 1). The most frequent causative agents of UTIs in the study of 15-30 age group reported as E. coli (20.58\%) and Klebsiella (14.7\%) followed by Pseudomonas $(11.7 \%)$ and Acinetobacter (2.9\%). Similar pattern also was observed in 31-45 age group E. coli (31.5\%) and Klebsiella (15.7\%) followed by Pseudomonas $(10.5 \%)$. Gram positive were found $24.5 \%$ in total samples. In which age group 15-30 years of women showed $23.5 \%$ gram positive isolates while $26.3 \%$ recorded prominent prevalence in age group 31-45 years women. The most frequent gram positive causative agents in the study were found to be Coagulase negative staphylococci and
Staphylococcus aureus followed by and Enterococcus faecalis. In the study of 15-30 age group was found to be Coagulase negative staphylococci (8.8\%) and Staphylococcus aureus $(8.8 \%)$ followed by Enterococcus faecalis (5.8\%). Similar pattern also was observed in 31-45 age group Coagulase negative staphylococci (15.7\%) and Staphylococcus aureus (10.5\%).

In this study, fungal infection of Candida was also found to be as a causative agent of UTI. The total percentage of fungal infection incidence was $22.6 \%$. In age group 15-30 years women showed higher (26.4\%) incidence of UTI than age group 31-45 which was found to be $15.7 \%$ (Table 1).

Figure 1 shows the sensitivity of gram negative isolates to antibiotics used showed the highest sensitivity to Norfloxacin with percentage $(92.86 \%)$ followed by Nitrofurantoin with percentage (89.29\%), Levofloxacin $(82.14 \%)$ while the proportion was less sensitive to Ampicillin with percentage $(39.29 \%)$. It was the proportion of resistance to Ampicillin Cefazolin (32.14\%, $32.1 \%)$ followed by Gentamicin (21.43\%) Ofloxacin $(10.71 \%)$ Nitrofurantoin $(10.71 \%)$.

In gram positive isolates, the sensitivity to antibiotics indicated the highest sensitivity to Norfloxacin $(100 \%)$ followed by Gentamicin (92.31\%), Ofloxacin (84.62\%). The less sensitive antibiotic was Ampicillin with percentage (38.46). It was reported that in all antibiotics Ampicillin was showed highest resistant pattern followed by Cefoxitin (23.08\%), Ofloxacin (15.38\%) and Gentamicin (7.69\%). Norfloxacin was not reported any resistance pattern against isolates (Fig. 2).

Figure 3 showed antifungal susceptibility test against antifungal drug Amphotericin B, Voriconazole, Fluconazole and Itraconazole. 
Amphotericin B indicated highest sensitivity pattern with percentage $91.67 \%$ followed by Voriconazole (83.3\%), Fluconazole (83.3\%) and Itraconazole (66.7\%). The highest resistant pattern reported in Itraconazole (16.67\%) followed by Fluconazole $(8.3 \%)$ and Voriconazole (8.3\%). Amphotericin B was demonstrated no resistant pattern against isolates.

\section{Nagwan slum}

The 51 samples of highly symptomatic women were collected from Nagwan slum. The result showed that the overall prevalence of UTIs in both age groups was $45 \%$. In which, occurrence of UTI in 15-30 age group was found upto $52.2 \%$ while $31-45$ age group showed $47.8 \%$. Thus, $15-30$ age group show increased risk of infection than 31-45 age group females (Table 2). Almost all of the cases of UTIs were due to the gram negative bacteria with no prominent age group difference (Table 2). The percentage of gram negative bacteria was $52.2 \%$. The percentage of Lactose fermenting bacteria was $91.6 \%$. Lactose fermenting (91.6 \%) bacteria indicated predominant frequency in both age groups. Non lactose fermenting bacteria was observed $14.2 \%$. The most frequent causative agents of UTIs in the study of 15-30 age groups reported as E. coli (33.3\%) and Klebsiella $(8.3 \%)$ followed by Pseudomonas (8.3\%) and Acinetobacter (8.3\%) but in 31-45 age group Klebsiella (27.27\%) was commonest UTI pathogens then E. coli $(18.2 \%)$ in Nagawan slum.

Gram positive were found $26.1 \%$ in total samples. In which age group 15-30 years of women showed $25 \%$ gram positive isolates while $27.3 \%$ recorded prominent prevalence in age group 31-45 years women. The most frequent gram positive causative agents in the study were found to be Coagulase negative staphylococci and Staphylococcus aureus. In the study of 15-30 age group was found to be
Staphylococcus aureus (16.6 \%) and Coagulase negative staphylococci $(8.3 \%)$ but in 31-45 age group Coagulase negative staphylococci $(27.3 \%)$ was more common pathogen for UTI.

The study was also noted that fungal infection of Candida was also found to be as a causative agent of UTI. The total percentage of fungal infection incidence was $21.7 \%$. In age group 31-45 years women showed higher (27.3\%) incidence of UTI than age group 15-30 which was found to be $16.66 \%$

Figure 4 shows Norfloxacin Nitrofurantoin and Levofloxacin antibiotics were used that showed the highest sensitivity of gram negative isolates while the proportion was less sensitive to Cefazolin and Ampicillin.

In gram positive isolates, the sensitivity to antibiotics indicated the highest sensitivity to Norfloxacin (100\%) followed by Ampicillin, Cefoxitin, Gentamicin and Ofloxacin but data also revealed that Ampicillin was resistant with percentage of 16.67 . It was reported that in all antibiotics Ampicillin and Cefoxitin was showed highest resistant pattern. Norfloxacin, Gentamicin and Ofloxacin were not reported any resistance pattern against isolates (Fig. 5).

Figure 6 showed antifungal susceptibility test against antifungal drug Amphotericin B, Voriconazole, Fluconazole and Itraconazole. Amphotericin B indicated highest sensitivity pattern with percentage $100 \%$ followed by Voriconazole (80\%), Itraconazole $(80 \%)$ and Fluconazole $(60 \%)$. The highest resistant pattern reported in Itraconazole and Fluconazole. Amphotericin B and Voriconazole were demonstrated no resistant pattern against isolates.

\section{Bajardeehan slum}

The 115 samples of highly symptomatic women were then collected from Bajardeehan 
slum. Samples were cultured in laboratory and then organized in different age groups. The result showed that the overall prevalence of UTIs in both age groups was $49.5 \%$. In which, occurrence of UTI in 15-30 age group was found upto $57.8 \%$ while $31-45$ age group showed $42.1 \%$. Thus, $15-30$ age group show increased risk of infection than 31-45 age group females (Table 3 ).

Almost all of the cases of UTIs were due to the gram negative bacteria with no prominent age group difference (Table 3). The percentage of gram negative bacteria was $57.9 \%$. The percentage of Lactose fermenting bacteria was $81.2 \%$.

Lactose fermenting $(81.2 \%)$ bacteria indicated predominant frequency in both age groups. Non lactose fermenting bacteria was observed $18.2 \%$. The age group 15-30 years females demonstrated about two folds increase of NLF than 31-45 age group females. The most frequent causative agents of UTIs in the study of 15-30 age group reported as E. coli (24.2\%) and Klebsiella (15.2\%) followed by Pseudomonas (12.1\%) and Enterobacter (6.1\%).

Similar pattern also was observed in 31-45 age group E. coli (29.2\%) and Klebsiella (16.6\%) followed by Pseudomonas (8.3\%) Enterobacter (4.1\%). Gram positive were found $22.8 \%$ in total samples. In which age group 15-30 years of women showed $21.2 \%$ gram positive isolates while $25 \%$ recorded prominent prevalence in age group 31-45 years women.

The most frequent gram positive causative agents in the study were found to be Staphylococcus aureus (12.1\%) and Coagulase negative staphylococci (9.1) in 1530 age group but Coagulase negative staphylococci (16.6\%) was observed higher than Staphylococcus aureus (8.3\%).
In this study, fungal infection of Candida was also found to be as a causative agent of UTI. The total percentage of fungal infection incidence was $19.2 \%$. In age group 15-30 years women showed higher (12.1\%) incidence of UTI than age group 31-45 which was found to be $4.1 \%$. The sensitivity of gram negative isolates to antibiotics used that showed the highest sensitivity to Norfloxacin and Levofloxacin with percentage (90.91\%) followed by Nitrofurantoin with percentage (87.9\%), Gentamicin (75.8\%) and Ofloxacin $(72.7 \%)$ while the proportion was less sensitive to Ampicillin with percentage (63.6\%) (Fig. 7).

It was the proportion of resistance to Gentamicin (32.1\%) followed by Ampicillin, Ofloxacin, Cefazolin and Levofloxacin. Ampicillin was indicated highest intermediate sensitivity $(27.3 \%)$.

In gram positive isolates, the sensitivity to antibiotics indicated the highest sensitivity to Norfloxacin $(92.3 \%)$ followed by Ofloxacin, Cefoxitin.

The less sensitive antibiotic was Ampicillin with percentage $(61.5 \%)$. It was reported that in all antibiotics Ampicillin (23.1\%) was showed highest resistant pattern. Gentamicin $(23.1 \%)$ was indicated intermediate sensitivity against isolates (Fig. 8).

Figure 9 showed antifungal susceptibility test against antifungal drug Amphotericin B, Voriconazole, Fluconazole and Itraconazole. Amphotericin B indicated highest sensitivity pattern with percentage $90.9 \%$ followed by Voriconazole (81.8\%), Fluconazole $(63.3 \%)$ and Itraconazole (54.7\%). The highest resistant pattern reported in Itraconazole (36.4\%) followed by Fluconazole $(27.3 \%)$ and Voriconazole (9.1\%). Amphotericin B was demonstrated no resistant pattern against isolates. 
Table.1 Prevalence of different isolates of bacteria and fungi in both groups of Ravidrapuri slum

\begin{tabular}{|c|c|c|c|c|c|}
\hline \multicolumn{2}{|c|}{ Types of Microorganisms } & \multicolumn{2}{|l|}{$15-30$} & \multicolumn{2}{|l|}{$31-45$} \\
\hline & & \multirow{2}{*}{$\begin{array}{l}\text { No. of } \\
\text { isolates } \\
7\end{array}$} & \multirow{2}{*}{$\begin{array}{l}\text { Percentage } \\
20.58\end{array}$} & \multirow{2}{*}{$\begin{array}{l}\text { No. of } \\
\text { isolates } \\
6\end{array}$} & \multirow{2}{*}{$\begin{array}{l}\text { Percentage } \\
31.5\end{array}$} \\
\hline Gram Negative & Escherichia coli & & & & \\
\hline & Klebsiella pneumoniae & 5 & 14.7 & 3 & 15.7 \\
\hline & $P$. aeruginosa & 4 & 11.7 & 2 & 10.5 \\
\hline & Acinetobacter & 1 & 2.9 & 0 & 0 \\
\hline \multirow[t]{3}{*}{ Gram positive } & Staphylococcus aureus & 3 & 8.8 & 2 & 10.5 \\
\hline & $\begin{array}{l}\text { Coagulase negative } \\
\text { Staphylococci }\end{array}$ & 3 & 8.8 & 3 & 15.7 \\
\hline & Enterococcus faecalis & 2 & 5.8 & 0 & 0 \\
\hline Fungi & Candida & 9 & 26.4 & 3 & 15.7 \\
\hline
\end{tabular}

Table.2 Prevalence of different isolates of bacteria and fungi in both groups of Nagwan slum

\begin{tabular}{|c|c|c|c|c|c|}
\hline \multirow{2}{*}{\multicolumn{2}{|c|}{ Types of Microorganisms }} & \multicolumn{2}{|l|}{ 15-30 } & \multicolumn{2}{|l|}{$31-45$} \\
\hline & & $\begin{array}{l}\text { No. of } \\
\text { isolates }\end{array}$ & Percentage & $\begin{array}{l}\text { No. of } \\
\text { isolates }\end{array}$ & Percentage \\
\hline \multirow[t]{4}{*}{ Gram Negative } & Escherichia coli & 4 & 33.3 & 2 & 18.18 \\
\hline & K.pneumoniae & 1 & 8.3 & 3 & 27.27 \\
\hline & P. aeruginosa & 1 & 8.3 & 0 & 0 \\
\hline & Acinetobacter & 1 & 8.3 & 0 & 0 \\
\hline \multirow[t]{3}{*}{ Gram positive } & S.aureus & 2 & 16.6 & 0 & 0 \\
\hline & $\begin{array}{l}\text { Coagulase negative } \\
\text { Staphylococci }\end{array}$ & 1 & 8.3 & 3 & 27.27 \\
\hline & E.faecalis & 0 & 0 & 0 & 0 \\
\hline Fungi & Candida & 2 & 16.6 & 3 & 27.27 \\
\hline
\end{tabular}

Table.3 Prevalence of different isolates of bacteria and fungi in both groups of Bajardeehan slum

\begin{tabular}{|c|c|c|c|c|c|}
\hline \multirow{2}{*}{\multicolumn{2}{|c|}{ Types of Microorganisms }} & \multicolumn{2}{|l|}{$15-30$} & \multicolumn{2}{|l|}{$31-45$} \\
\hline & & \multirow{2}{*}{$\begin{array}{l}\text { No. of } \\
\text { isolates } \\
8\end{array}$} & \multirow{2}{*}{$\begin{array}{l}\text { Percentage } \\
24.24\end{array}$} & \multirow{2}{*}{$\begin{array}{l}\text { No. of } \\
\text { isolates } \\
7\end{array}$} & \multirow{2}{*}{$\begin{array}{l}\text { Percentage } \\
29.16\end{array}$} \\
\hline Gram Negative & Escherichia coli & & & & \\
\hline & K.pneumoniae & 5 & 15.15 & 4 & 16.6 \\
\hline & P. aeruginosa & 4 & 12.12 & 2 & 8.3 \\
\hline & Acinetobacter & 0 & 0 & 0 & 0 \\
\hline \multirow[t]{3}{*}{ Gram positive } & E.aerogenes & 2 & 6.06 & 1 & 4.1 \\
\hline & S.aureus & 4 & 12.12 & 2 & 8.3 \\
\hline & $\begin{array}{l}\text { Coagulase negative } \\
\text { Staphylococci }\end{array}$ & 3 & 9.09 & 4 & 16.6 \\
\hline Fungi & E.faecalis & 0 & 0 & 0 & 0 \\
\hline
\end{tabular}


Table.4 Prevalence of different isolates of bacteria and fungi in both groups of Batuapura slum

\begin{tabular}{|c|c|c|c|c|c|}
\hline \multirow{2}{*}{\multicolumn{2}{|c|}{ Types of Microorganisms }} & \multicolumn{2}{|l|}{$15-30$} & \multicolumn{2}{|l|}{$31-45$} \\
\hline & & \multirow{2}{*}{$\begin{array}{l}\text { No. of } \\
\text { isolates } \\
3\end{array}$} & \multirow{2}{*}{$\begin{array}{l}\text { Percenta } \\
\text { ge } \\
15.17\end{array}$} & \multirow{2}{*}{$\begin{array}{l}\text { No. of } \\
\text { isolates } \\
5\end{array}$} & \multirow{2}{*}{$\begin{array}{l}\text { Percent } \\
\text { age } \\
25\end{array}$} \\
\hline Gram Negative & Escherichia coli & & & & \\
\hline & K.pneumoniae & 1 & 5.2 & 4 & 20 \\
\hline & P. aeruginosa & 1 & 5.2 & 1 & 5 \\
\hline & Acinetobacter & 1 & 5.2 & 0 & 0 \\
\hline \multirow[t]{3}{*}{ Gram positive } & E.aerogenes & 2 & 10.52 & 1 & 5 \\
\hline & Staphylococcus aureus & 2 & 10.52 & 4 & 20 \\
\hline & CONS & 2 & 10.52 & 0 & 0 \\
\hline Fungi & E. faecalis & 2 & 10.52 & 2 & 10 \\
\hline
\end{tabular}

Table.5 Prevalence of different isolates of bacteria and fungi in both groups of Ghasiyari Tola slum

\begin{tabular}{|c|c|c|c|c|c|}
\hline \multirow{2}{*}{\multicolumn{2}{|c|}{ Types of Microorganisms }} & \multirow{2}{*}{\multicolumn{2}{|c|}{ 15-30 }} & \multirow{2}{*}{\multicolumn{2}{|c|}{$31-45$}} \\
\hline & & & & & \\
\hline Gram & Escherichia coli & $\begin{array}{l}\text { No. of } \\
\text { isolates } \\
3\end{array}$ & \begin{tabular}{|l|} 
Percentage \\
75 \\
\end{tabular} & $\begin{array}{l}\text { No. of } \\
\text { isolates } \\
3\end{array}$ & $\begin{array}{l}\text { Percentage } \\
42\end{array}$ \\
\hline Negative & Klebsiella pneumoniae & 1 & 25 & 0 & 0 \\
\hline & P. aeruginosa & 0 & 0 & 0 & 0 \\
\hline & Acinetobacter & 0 & 0 & 0 & 0 \\
\hline \multirow{3}{*}{$\begin{array}{c}\text { Gram } \\
\text { positive }\end{array}$} & E.aerogenes & 0 & 0 & 1 & 14.2 \\
\hline & S.aureus & 0 & 0 & 2 & 28.5 \\
\hline & Coagulase negative Staphylococci & 0 & 0 & 0 & 0 \\
\hline Fungi & E.faecalis & 0 & 0 & 0 & 0 \\
\hline
\end{tabular}

Fig.1 Antibiotic susceptibility pattern for gram negative bacteria of Ravindrapuri extension slum

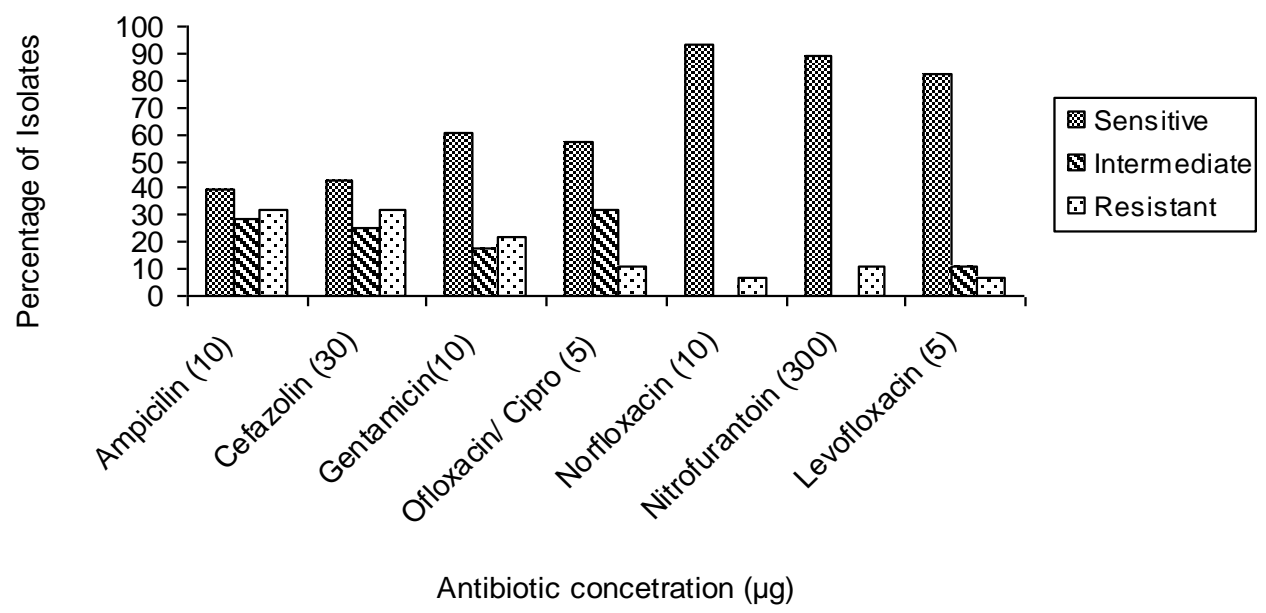


Fig.2 Antibiotic susceptibility pattern for gram positive bacteria of Ravindrapuri extension slum

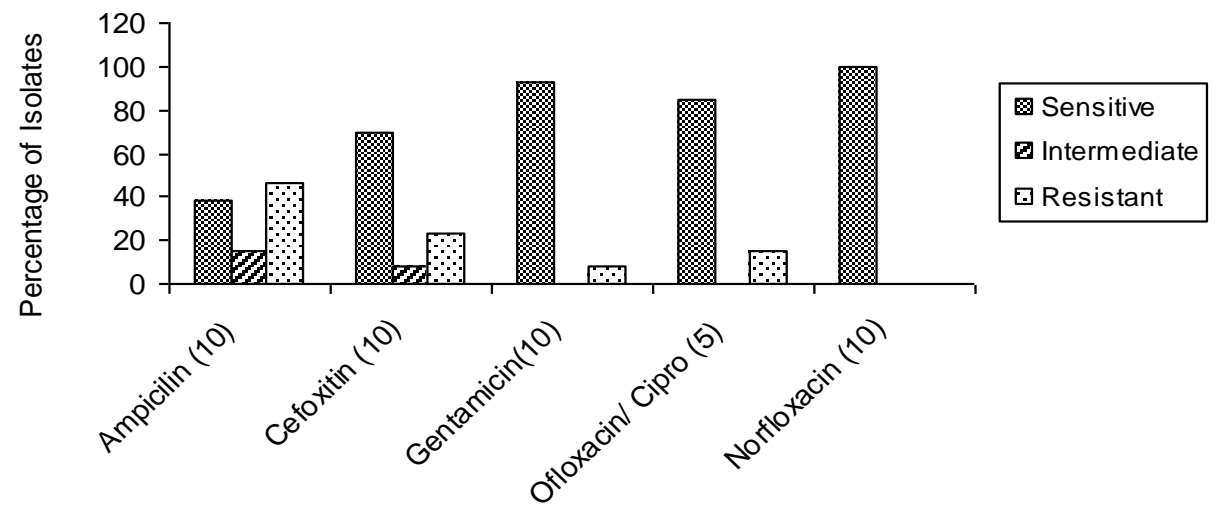

Antibiotic Concentration $(\mu \mathrm{g})$

Fig.3 Effect of antifungal drugs against isolated fungal Candida of Ravindrapuri extension slum women

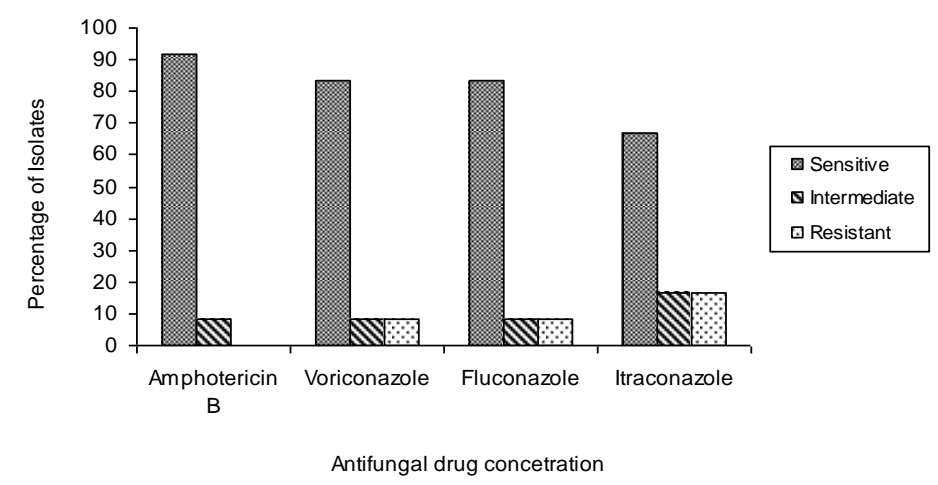

Fig.4 Antibiotic susceptibility pattern for gram negative bacteria of Nagwan slum

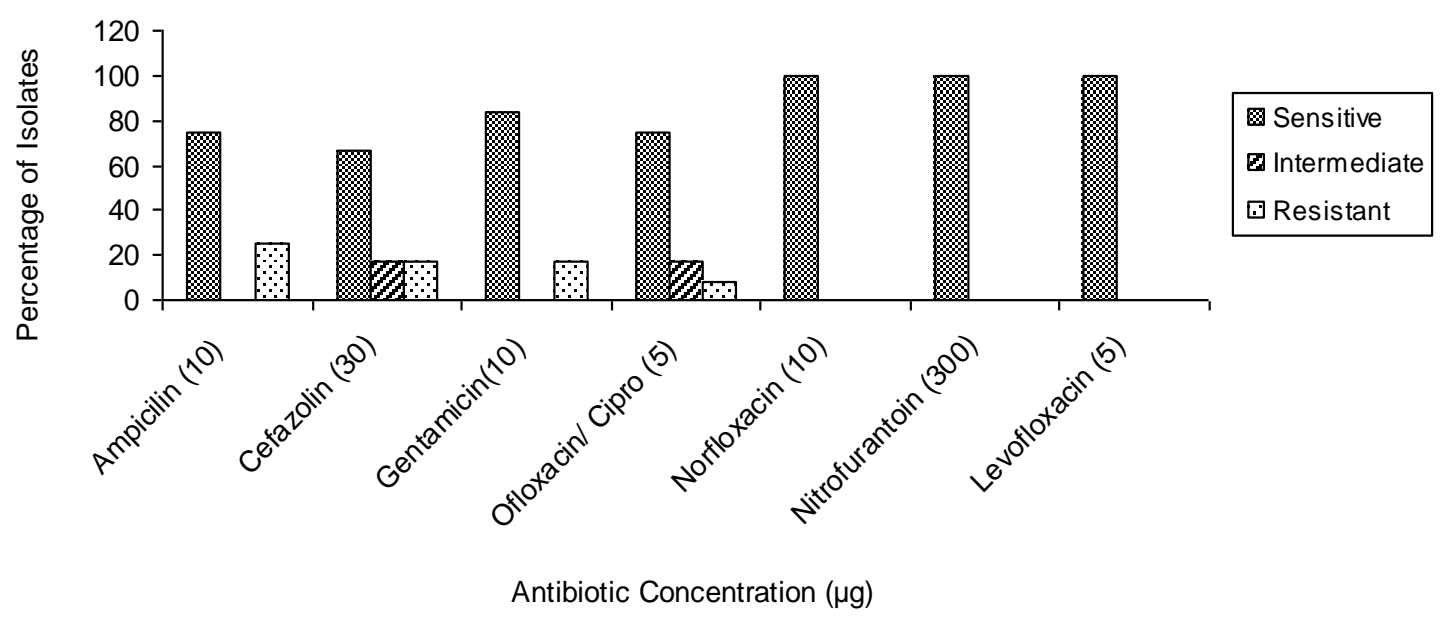


Fig.5 Antibiotic susceptibility pattern for gram positive bacteria of Nagwan slum

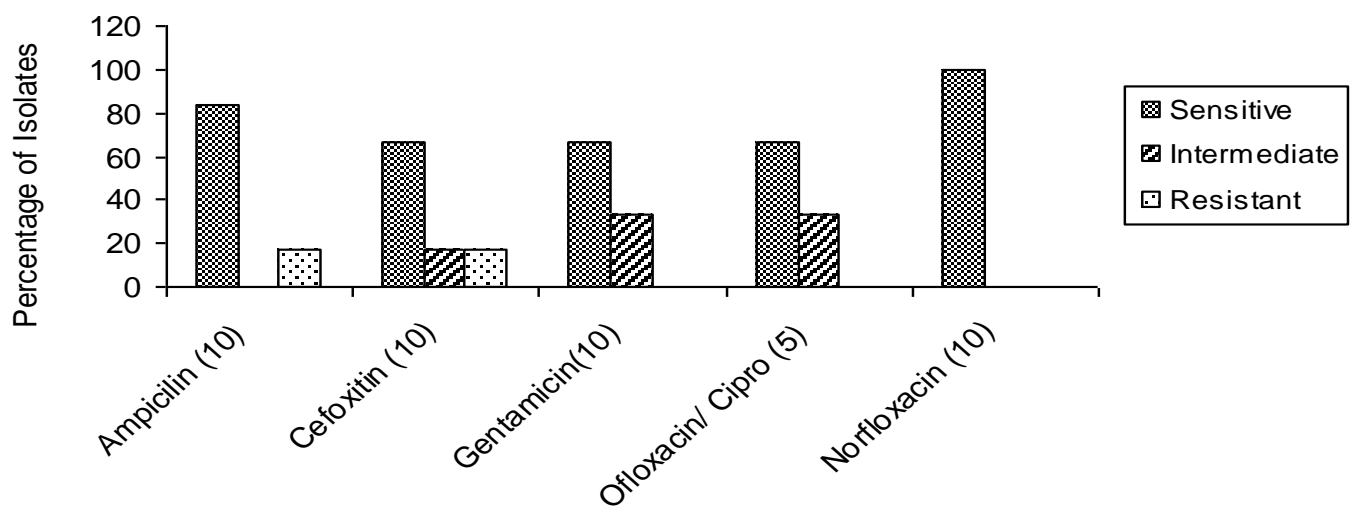

Antibiotic Concentration $(\mu \mathrm{g})$

Fig.6 Effect of antifungal drugs against isolated fungal Candida of Nagwan slum women

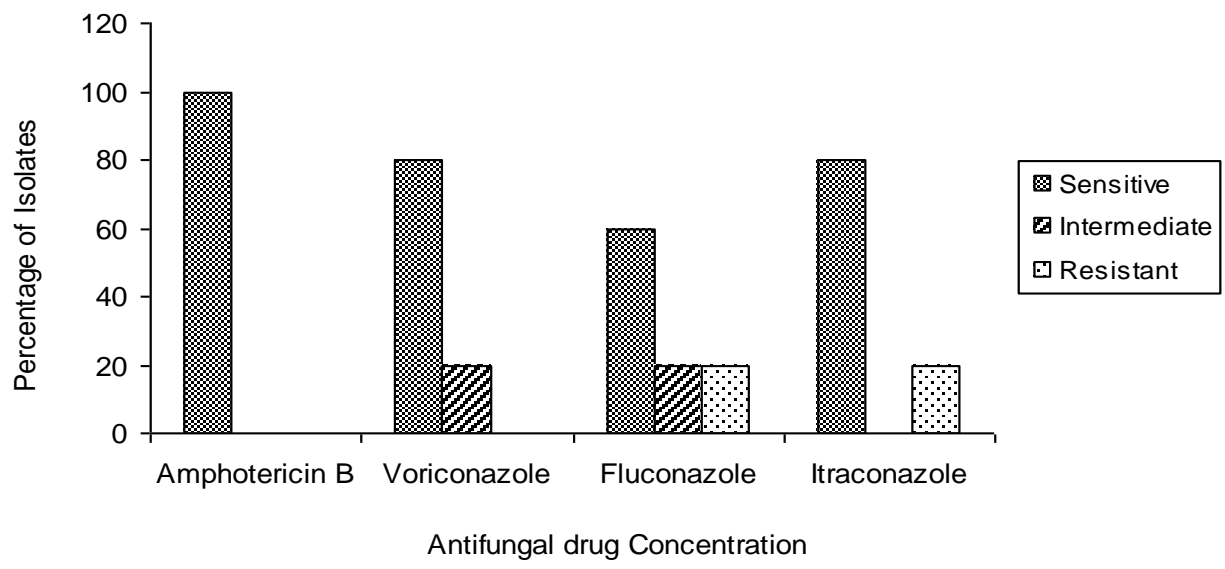

Fig.7 Antibiotic susceptibility pattern for gram negative bacteria of Bajardeehan slum

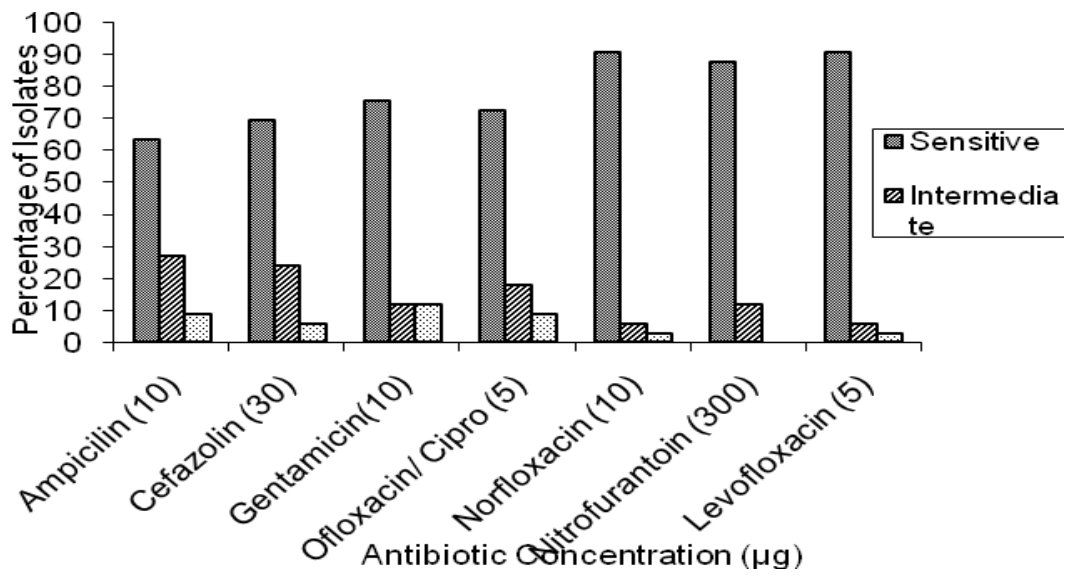


Fig.8 Antibiotic susceptibility pattern for gram positive bacteria of Bajardeehan slum

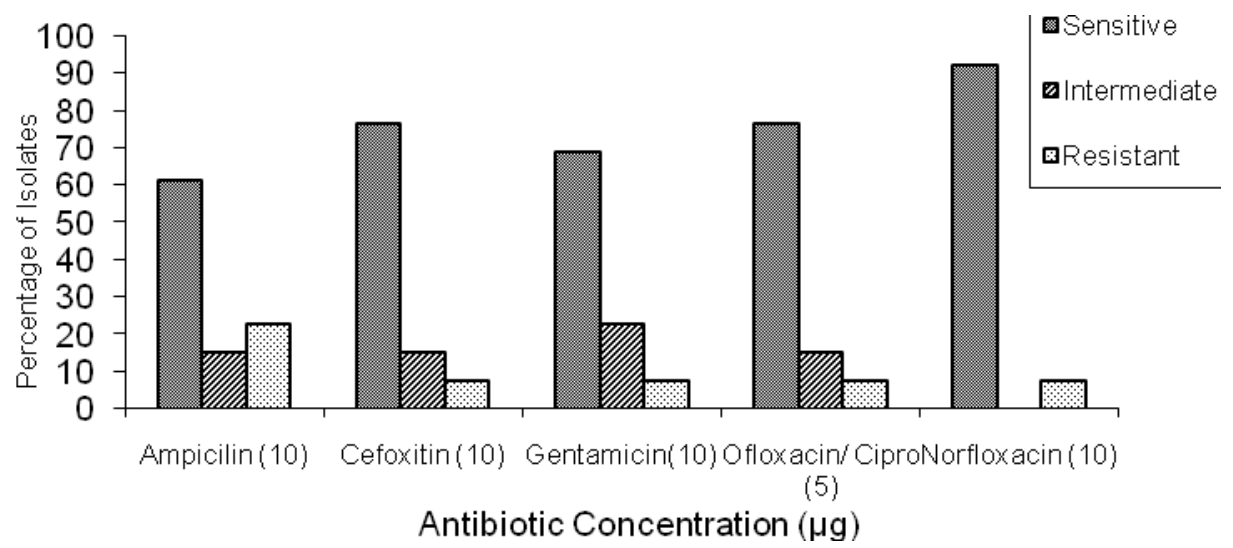

Fig.9 Effect of antifungal drugs against isolated fungal Candida of Bajardeehan slum women

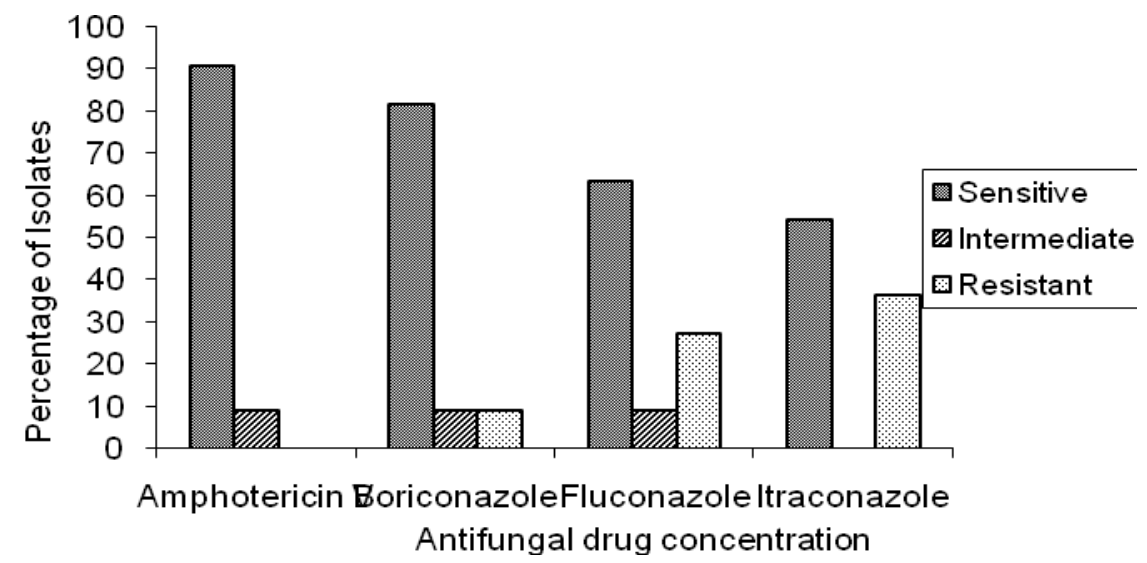

Fig.10 Antibiotic susceptibility pattern for gram negative bacteria of Batuapura slum

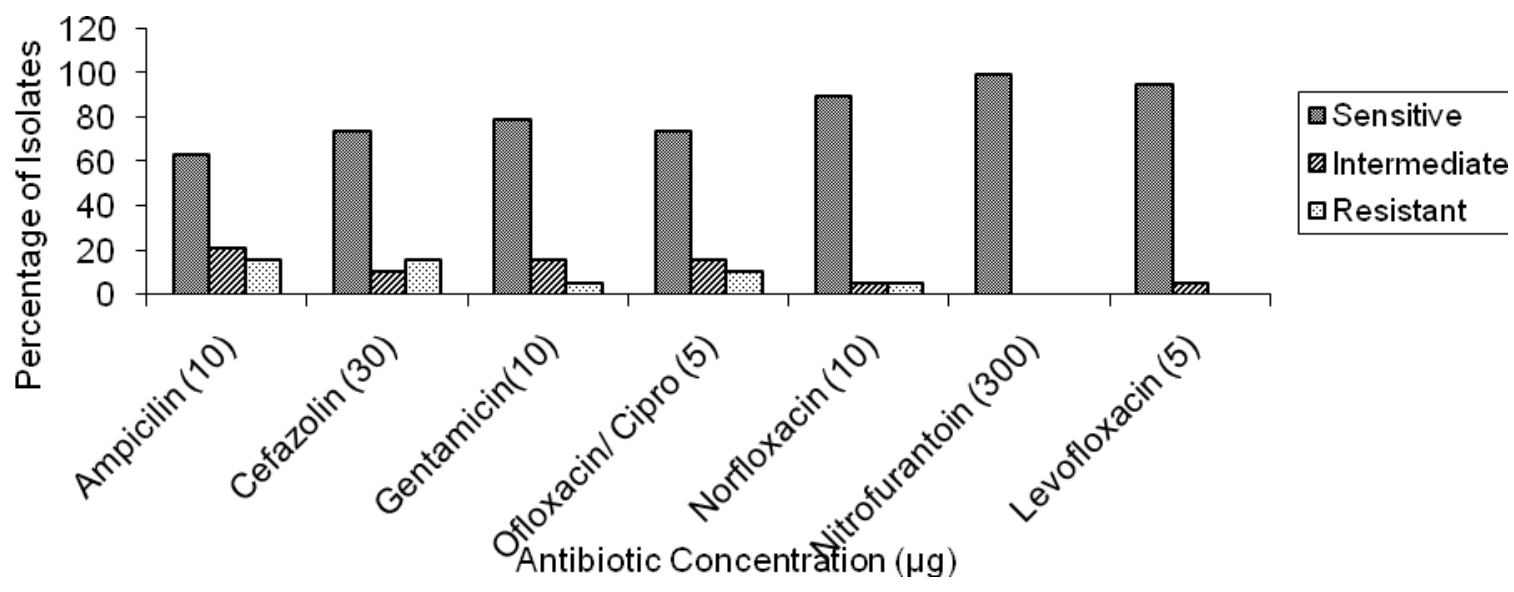


Fig.11 Antibiotic susceptibility pattern for gram positive bacteria of Batuapura slum

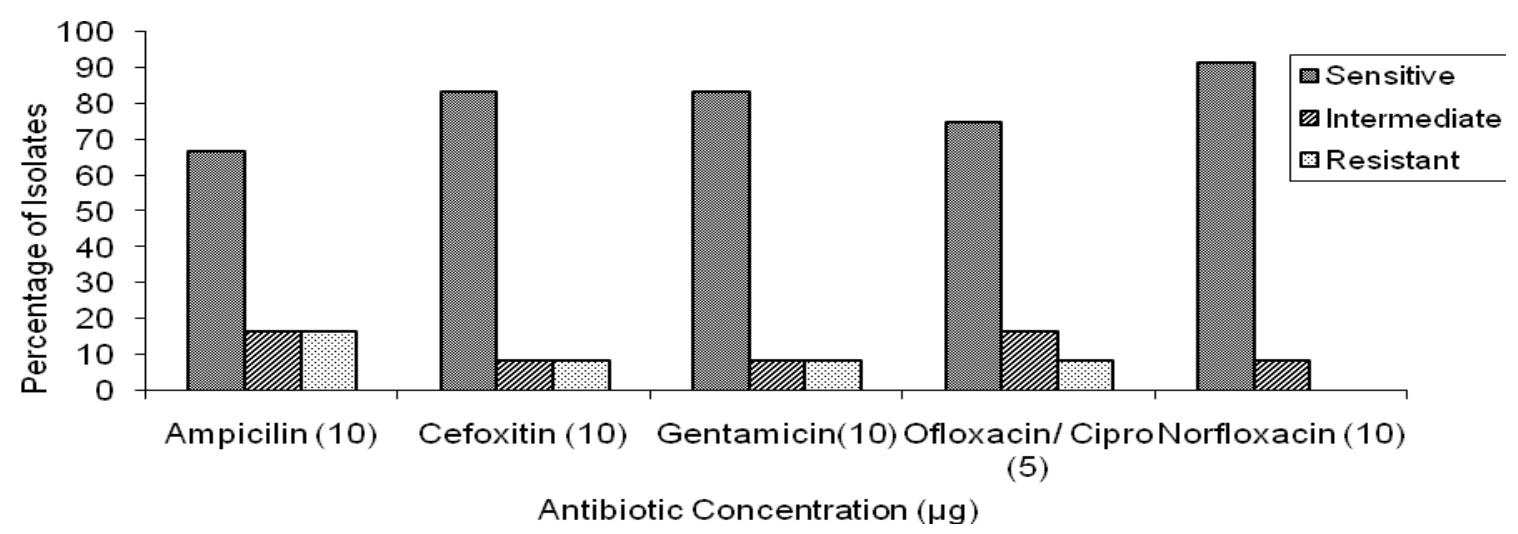

Fig.12 Effect of antifungal drugs against isolated fungal Candida of Batuapura slum women

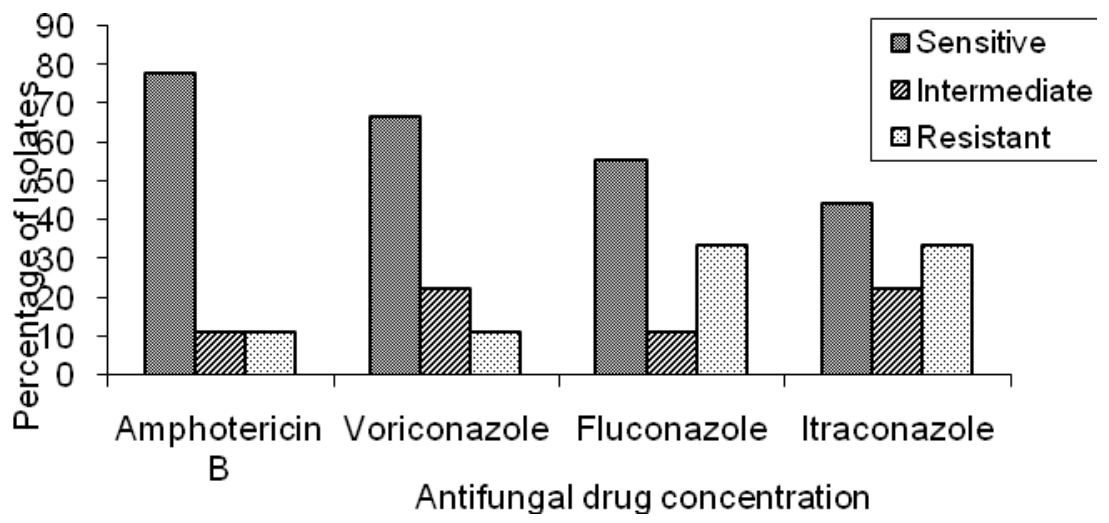

Fig.13 Antibiotic susceptibility pattern for gram negative bacteria of Ghasiyari Tola slum

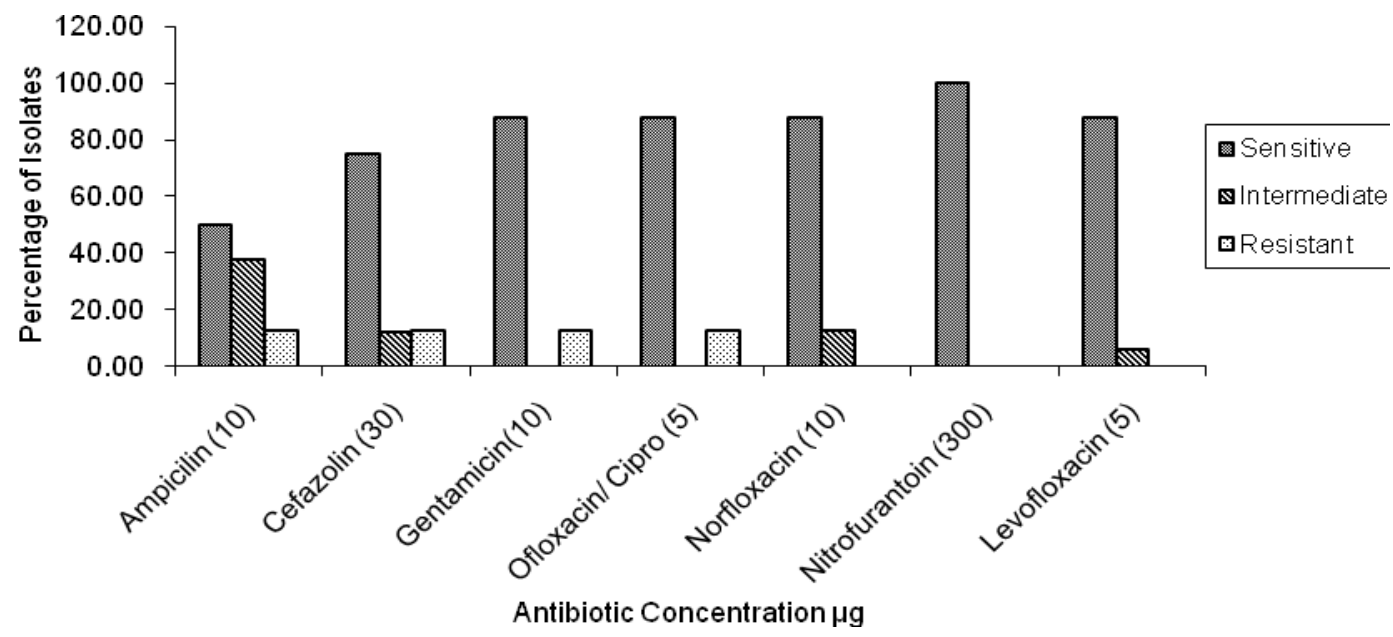


Fig.14 Antibiotic susceptibility pattern for gram positive bacteria of Ghasiyari Tola slum

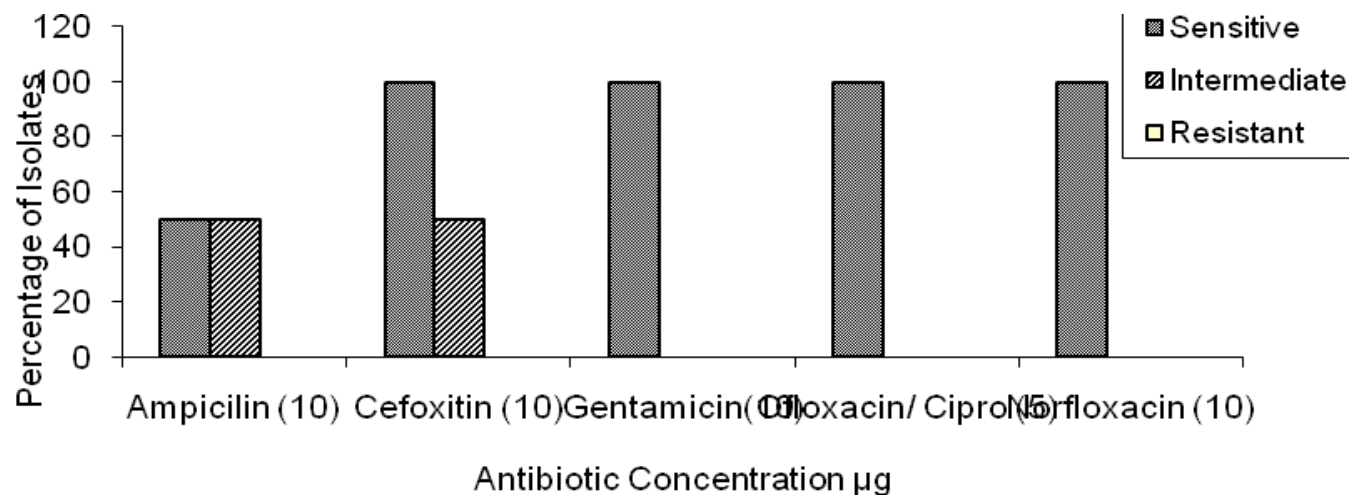

Fig.15 Effect of antifungal drugs against isolated fungal Candida of Batuapura slum women

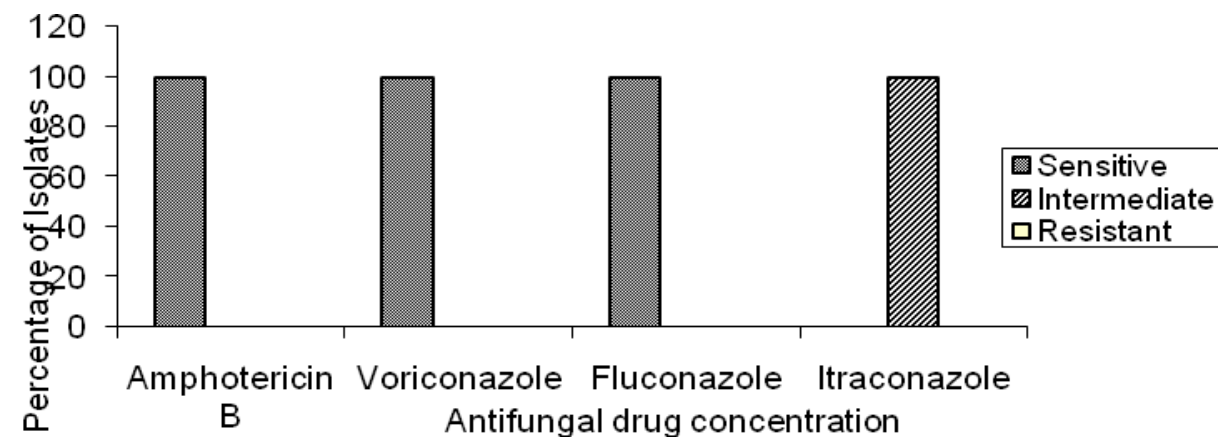

\section{Batuapura slum}

The 91 samples of highly symptomatic women were then collected from Batuapura slum. Samples were cultured in laboratory and then organized in different age groups. The result showed that the overall prevalence of UTIs in both age groups was $42 \%$. In which, occurrence of UTI in 15-30 age group was found upto 48.7\% while $31-45$ age group showed $51.3 \%$. Thus, 31-45 age group show increased risk of infection than 15-30 age group females (Table 4).

Almost all of the cases of UTIs were due to the gram negative bacteria with no prominent age group difference (Table 4). The percentage of gram negative bacteria was $48.7 \%$. The percentage of Lactose fermenting bacteria was $89.4 \%$. Lactose fermenting (89.4\%) bacteria indicated predominant frequency in both age groups. Non lactose fermenting bacteria was observed $10.5 \%$.

The most frequent causative agents of UTIs in the study of 15-30 age group reported as E. coli (15.2\%) followed by Enterobacter (10.5\%).

Gram positive were found $30.8 \%$ in total samples. In which age group 15-30 years of women showed $31.5 \%$ gram positive isolates while $30 \%$ recorded prominent prevalence in age group 31-45 years women. Coagulase negative staphylococci, Staphylococcus aureus and Enterococcus faecalis were found with equal frequency in age group15-30. In the study of 31-45 age group was found to be Staphylococcus aureus $(20 \%)$ followed by Enterococcus faecalis (10\%). Coagulase negative staphylococci were not present in this group. 
In this study, fungal infection of Candida was also found to be as a causative agent of UTI. The total percentage of fungal infection incidence was $23.1 \%$. In age group $15-30$ years women showed higher $(26.5 \%)$ incidence of UTI than age group 31-45 which was found to be $20 \%$ (Table 4 ).

Figure 10 shows the sensitivity of gram negative isolates to antibiotics used showed the highest sensitivity to Nitrofurantoin with percentage (100\%), Levofloxacin $(94.7 \%)$ while the proportion was less sensitive to Ampicillin with percentage $(63.2 \%)$. It was the proportion of resistance to Ampicillin Cefazolin followed by Ofloxacin, Gentamicin and Norfloxacin.

In gram positive isolates, the sensitivity to antibiotics indicated the highest sensitivity to Norfloxacin $(91.7 \%)$ followed by Gentamicin, Cefoxitin Ofloxacin. The less sensitive antibiotic was Ampicillin with percentage $(66.7 \%)$. It was reported that in all antibiotics Ampicillin was showed highest resistant pattern followed by Cefoxitin, Ofloxacin and Gentamicin. Norfloxacin was not reported any resistance pattern against isolates (Fig. 11).

Figure 12 showed antifungal susceptibility test against antifungal drug Amphotericin B, Voriconazole, Fluconazole and Itraconazole against Candida. Amphotericin B indicated highest sensitivity pattern with percentage $77.8 \%$ followed by Voriconazole (66.7\%), Fluconazole (55.6\%) and Itraconazole (44.4\%). The highest resistant pattern reported in Itraconazole Fluconazole followed by Voriconazole Amphotericin B against isolates (Fig. 12).

\section{Ghasiyari Tola}

The 31 samples of highly symptomatic women were then collected from Ghasiyaritola slum. Samples were cultured in laboratory and then organized in different age groups. The result showed that the overall prevalence of UTIs in both age groups was $35.5 \%$. In which, occurrence of UTI in 15-30 age group was found upto $37.36 \%$ while $31-45$ age group showed $63.6 \%$. Thus, 31-45 age group show increased risk of infection than 15-30 age group females. Women of 31-45 years age group were reported to have two folds increase UTI as compared to the 15-30 age groups (Table 5).

Almost all of the cases of UTIs were due to the gram negative bacteria with no prominent age group difference (Table 5). The percentage of gram negative bacteria was $72.7 \%$. The percentage of Lactose fermenting bacteria was $72.7 \%$. Lactose fermenting $(72.7 \%)$ bacteria indicated predominant frequency in both age groups. The most frequent causative agents of UTIs in the study of 15-30 age groups reported as E. coli $(75 \%)$ and Klebsiella (25\%). In 31-45 age group E. coli (42\%) were found as more causative agent for UTI followed by Enterobacter (14.2\%).

Gram positive were found $18.1 \%$ in total samples. In which age group 15-30 years of women showed no gram positive isolates while $28.5 \%$ recorded prominent prevalence in age group 31-45 years women. The most frequent gram positive causative agents were only Staphylococcus aureus in 31-45 age groups.

In this study, fungal infection of Candida was also found to be as a causative agent of UTI. The total percentage of fungal infection incidence was $9 \%$. In age group 31-45 Candida were found upto $14.2 \%$ (Table 5).

Figure 13 shows the sensitivity of gram negative isolates to antibiotics used showed the highest sensitivity to Nitrofurantoin followed by Gentamicin, Levofloxacin, Oflaxacin while the proportion was less sensitive to Ampicillin with percentage $(50 \%)$. It was the proportion of resistance to Ampicillin, Cefazolin, Gentamicin and Ofloxacin. Nitrofurantoin, Nitrofloxacin and Levofloxacin indicated no resistant pattern against isolates.

In gram positive isolates, the sensitivity to antibiotics indicated the highest sensitivity to Norfloxacin, Gentamicin, Ofloxacin and 
Cefoxitin. The less sensitive antibiotic was Ampicillin. It was reported that in all antibiotics Ampicillin and Cefoxitin were noted intermediate Sensitivity pattern. All antibiotics were not reported any resistance pattern against isolates (Table 5). Figure 15 showed antifungal susceptibility test against antifungal drug Amphotericin B, Voriconazole, Fluconazole and Itraconazole. Amphotericin B, Voriconazole and Fluconazole indicated high sensitivity pattern. The highest resistant pattern reported in Itraconazole only. All other antibiotics were not demonstrated any resistant pattern against isolates.

It is concluded that both gram-negative and gram-positive bacteria were responsible for urinary tract infections and most of the strains were multi-drugs resistant. The most common isolated bacteria from urinary tract infections was $E$. coli and $S$. aureus and the most effective antimicrobial agents were Norfloxacin Nitrofurantoin and Levofloxacin against Gramnegative isolates and also the most effective antifungal susceptibility test against antifungal drug Amphotericin B, Voriconazole, Fluconazole and Itraconazole was observed against Candida. As we found that there was lack of education and their position in male dominated society is very low. Also they do not understand the basic health related terminologies. So there is an urgent need of proper communication with help of some posters, models, picture, animation and play which can be possibly provided by some local Non-Governmental Organization.

\section{Acknowledgments}

Thanks: The authors would like to thank
Department of Science and Technology, New Delhi (Government of India) for financial support for this project (SEED/DISHA/WOSB/020/2012/G). We are thankful to the Department of Microbiology, Institute of Medical Sciences, Banaras Hindu University, Varanasi for providing necessities of this work.

\section{References}

Jha, D.K. and Tripathi, V.K., 2014. Quality of Life in Slums of Varanasi City: A Comparative Study, Transactions 36, (2) 171-182.

Rao, P. Padmanabha, 1999. Urbanization in Telangana and Its Future Implications, Rao, R. Ram Mohan and Simhadri, S. (eds): Indian Cities: Towards Next Millennium, Rawat Publication, Jaipur

Ronald, A. 2002. The etiology of urinary tract infection: Traditional and emerging pathogens. Am J Med. 113(1A): 14S-9S.

Stamm, W.E., Norrby, S.R., 2001. Urinary tract infections: disease panorama and challenges. J Infect Dis. 183 (1), S1-S4.

Standing Medical Advisory Sub-group on Antimicrobial Resistance (1998). The path of least resistance. London: $\mathrm{DoH}$; 1998.

Stapleton, A., 1999. Prevention of recurrent urinary-tract infections in women. Lancet, 353 (9146), 7-8.

Tripathi, V.K. 2011. Urban poor living in slums of Varanasi city, Sharma, P. R., Yadava R.S., Sharma V.N. (eds.): Research methodology: Concepts and Studies, RK BOOKS, New Delhi, Pages 493-515.

\section{How to cite this article:}

Bharti Singh, Deepmala Katiyar, Ragini Tilak, Ratan Kumar Srivastava and Rajveer Singh Chauhan. 2018. Prevalence of Urinary Tract Infection Causing Microorganism and Determination of Susceptibility to Antibiotic among Slum Women of District Varanasi. Int.J.Curr.Microbiol.App.Sci. 7(02): 3483-3497. doi: https://doi.org/10.20546/ijcmas.2018.702.415 